\title{
PERFIL BACTERIANO E RESISTÊNCIA A ANTIBIÓTICOS PADRÕES EM GESTANTES COM BACTERIÚRIA SINTOMÁTICA E ASSINTOMÁTICA NO DISTRITO FEDERAL
}

\author{
Eduardo Salloum Filho - CEUB, PIC/PIBIC CEUB, aluno bolsista \\ eduardo.salloum@sempreceub.com \\ Henrique Ramalho de Araújo Lemos Vieira - CEUB, PIC/PIBIC CEUB, aluno voluntário \\ hr.vieira.21@sempreceub.com
}

Fabíola Fernandes dos Santos Castro - CEUB, professora orientadora

fabiola.castro@ceub.edu.br

\begin{abstract}
A bacteriúria é definida pela presença de microrganismos na urina; clinicamente, é dividida em sintomática e assintomática e é prevalente em indivíduos do sexo feminino e em gestantes. O diagnóstico rápido e o tratamento precoce são essenciais durante a gestação, período de alterações anatômicas e fisiológicas que corroboram o quadro infeccioso. Uropatógenos podem ser prejudiciais à saúde da mãe e do feto, além de causar abortos. Conhecer o tipo de bactéria e a resistência aos antimicrobianos é fundamental para o tratamento adequado. O objetivo do estudo é verificar a prevalência de bacteriúria em gestantes residentes no Distrito Federal, a partir das Unidades Básicas de Saúde da Asa Norte (UBS 2) e da Asa Sul (UBS 1), por meio da coleta de urina e de informações obtidas por questionário, além da realização de urocultura e de provas bioquímicas e do perfil de resistência aos antibióticos utilizados na prática clínica, a partir do antibiograma das amostras positivas. Foram analisadas 63 amostras de urina no período de março a julho de 2021. Em laboratório, foi realizada a técnica de urocultura, as provas bioquímicas e o antibiograma. Posteriormente, os dados foram contabilizados junto às respostas dos formulários. Observou-se a $E$. coli como o uropatógeno mais prevalente, porém metade das amostras foi gram-positiva. Para o tratamento da E. coli, a ampicilina foi a menos eficaz; as amostras positivas eram resistentes; em gram-positivas, não houve resistência a nenhum dos antimicrobianos testados. Conclui-se a prevalência de $E$. coli nas gestantes com bacteriúria, a ampicilina como tratamento ineficaz e a necessidade da urocultura e do antibiograma para o tratamento efetivo.
\end{abstract}

Palavras-Chave: bacteriúria; gestantes; antibióticos; infecção urinária. 